\title{
Reseña: Sobre la segunda introducción a la Teoría de la ciencia de Johann G. Fichte
}

Sergio Bedoya Cortés

doi: http://dx.doi.org/ 10.18273/revfil.v19n1-2020005 (cc) († 


\section{Reseña: Sobre la segunda introducción a la Teoría de la ciencia de Johann G. Fichte* \\ Reseña: About the second introduction to the Theory of Science of Johann G. Fichte}

Forma de citar (APA): Bedoya-Cortés, S. (2020). Sobre la segunda introducción a la Teoría de la ciencia de Johann G. Fichte. Revista Filosofía UIS, 19(1), DOI: 10.18273/revfil.v19n1-2020005

Forma de citar (Harvard): Bedoya-Cortés, S. (2020). Sobre la segunda introducción a la Teoría de la ciencia de Johann G. Fichte. Revista Filosofía UIS, 19(1), 285-291.

Fecha de recepción: 19 de marzo de 2019

Fecha de aceptación: 8 de mayo de 2019

Sergio Bedoya Cortés: colombiano. Politólogo y magíster en Filosofía de la Universidad de los Andes, Colombia.

ORCID iD: orcid.org/0000-0003-3606-7605

Correo electrónico: sergiobc937@gmail.com 


\section{Reseña: Sobre la segunda introducción a la Teoría de la ciencia de Johann G. Fichte}

Después de haber entendido y estudiado algunos conceptos claves del criticismo y sus diferencias con el dogmatismo; gracias a la primera introducción a la teoría de la ciencia, Fichte busca en esta segunda introducción esbozar con mayor profundidad algunos de los planteamientos desarrollados en la primera introducción. Asimismo, intenta desenvolver algunos planteamientos nuevos sobre el idealismo en sí y sobre la relación entre criticismo y dogmatismo. Cabe recalcar que esta segunda introducción — dice Fichte — está dirigida a los lectores que ya poseen un sistema filosófico en su haber.

Así, el autor nos explica que la filosofía de la ciencia y el idealismo parten de que el objeto de su pensar no es un concepto muerto, a diferencia de las anteriores filosofías, ya que aquí es algo que posee conocimiento de sí mismo y por sí mismo. Por lo que la misión del filósofo - frente a esto- es la de poner ese algo vivo en una actividad adecuada; es decir, contemplarla, aprehenderla como algo único, expresado de maneras más claras: concebirla como absoluto. Es por lo anterior, que el filósofo debe fijar su atención en el fenómeno mismo y no en la forma o en el cómo este se presenta, ya que eso ha de ser asunto del objeto mismo. De igual modo, el autor nos explica que en esta filosofía existen dos formas de actuar, las cuales se pueden resumir de la siguiente manera: (i) la del Yo que observa el filósofo y (ii) las observaciones del filósofo. Dicha aclaración sobre la forma de actuar es fundamental debido a que en otras filosofías solo existe una forma determinada de actuar: actuar solo con los pensamientos del filósofo, esto se debe a que en estas filosofías la materia no se ha tomado jamás como algo pensante.

Después de dicha aclaración, el autor se pregunta por la forma de proceder desde el criticismo para resolver su problema, cosa a la que responderá diciendo que para esto se debe abstraer de todo ser, ya que aquí no se piensa un no-ser para negar el ser, sino que se piensa el concepto del ser de manera absoluta. Pero ante esto sigue faltando un algo, un elemento fundamental para el idealismo: falta el actor o el sujeto que practica dicha abstracción de todo ser pues, en el razonamiento filosófico, el filósofo solo se atiene a lo que él es consiente (esto es, al sujeto que ha de ser concebido como puro) para así mostrar el fundamento del 
ser general, libre de representaciones particulares. No obstante, al sujeto - por su abstracción misma de sí y para sí- le conviene actuar porque es desde allí desde donde se debe de aprehender, para así empezar con el ver y el ser, con lo real y lo ideal. Es decir, con la doble serie, es por esto que la conciencia de sí y la conciencia de algo diferente a nosotros mismos están unidas en conjunto. Pero el punto aquí es que la primera, la conciencia de sí, es la condición o fundamento, mientras que la segunda, la conciencia de lo real, está condicionada a la primera.

Sin embargo, sobre esta conciencia de sí no sabemos nada, no sabemos ni cómo es el Yo para sí mismo, ni sabemos qué corresponde en el acto de construir el Yo al filósofo en cuanto tal y es sobre esto que Fichte continúa su análisis. En primer lugar, el autor ha de explicarnos que para saber cómo es el Yo para sí mismo solo se puede tomar al Yo como un ser fuera de sí, pero ¿cómo se hace esto? Fichte nos dirá que el ser mismo ha de ser pensado y que en esta acción este ha de volver sobre sí mismo, cosa que resultará con el tomar al Yo mismo como su objeto mismo; y con esto sabremos ya el modo de construcción del Yo — conociendo su naturaleza para sí-. En segundo lugar, y frente a la pregunta de la correspondencia en el acto de construcción del yo al filósofo en cuanto tal, el autor nos dirá que al Yo corresponde solo el volver sobre sí, el resto -la abstracción y el pensar- corresponde al filósofo; para quien existe ya "como un mero hecho el sistema de la experiencia entera, que debe ser producido por el Yo delante de sus ojos, a fin de que pueda conocer su modo de originarse" (Fichte, 2013 p. 503). Pero, nuevamente, nuestro conocimiento ha sido intruso y curioso y por eso nos preguntamos ahora ¿qué es para el Yo volver sobre sí mismo? Como es costumbre en Fichte, comenzará por decirnos primero lo que no es: (i) no es un concepto, ya que esto surge gracias a la oposición del no-yo y la determinación del Yo; (ii) tampoco es una conciencia, ya que en dicha acción no ha de construirse nunca una conciencia, pues "el Yo es puesto [...] meramente en la posibilidad de la conciencia de sí, y con ella de toda conciencia restante; pero [aquí] no surge todavía ninguna conciencia real" (Fichte, 2013, p. 504). Este acto es solo una parte a abstraer por el filósofo de la acción de la inteligencia ya que de aquí es que se produce su conciencia y, por ende, el Yo que se construye a sí mismo es el Yo propio del filósofo.

Igualmente, Fichte nos explica que esta acción de la construcción del Yo propio es una acción objetiva. Y es que la objetividad del Yo se debe a que este tiene todavía algo más que su propio pensamiento de sí mismo y dicho pensamiento tiene por base algo más que el pensamiento y dicha construcción solo puede hacerse por medio del actuar, ya que se es libre, y este actuar precisamente -y no otro- es el concepto del Yo: es así, porque así lo hago. Además, podemos decir que en este acto - a diferencia del anterior que consistía en el volver a sí mismo por parte del Yo- se forma conciencia, esto se debe a que aquí no solo se intuye, sino también se forma concepto: "lo que sea actuar sólo puede intuirse [...] pero 
de lo que entra en esta intuición se forma concepto mediante el contraste con el mero ser" (Fichte, 2013, p. 505).

Sobre lo anterior nos sigue quedando una pregunta: ¿qué es la verdadera esencia aquí?, pregunta que solo puede responderse al volverse a la intuición. Para explicar este movimiento hemos de entender primero que al pensarse a sí mismo se requiere hacer algo de la espontaneidad y ¿qué es la espontaneidad?: es el actuar interior, por lo que se puede decir que si se piensa de manera espontánea se actúa. Pero si distinguimos este actuar del opuesto, entendiendo opuesto como el pensar objetos fuera de sí, el pensarse a sí mismo y el pensar la cosa o el objeto son opuestos. Igualmente podemos decir que el pensamiento de sí mismo es el pensamiento de la acción, mientras que la palabra Yo es el término que designa esta acción, por lo que aquí son idénticos el Yo y el actuar que vuelve sobre sí.

Si con el idealismo trascendental se supone que toda conciencia reposa en la conciencia de sí y está condicionada por ella, se tiene que pensar ese volver sobre sí como anterior a todos los demás actos de la conciencia (como primitivo) y como es para él lo que no es en su conciencia, debe pensarlo como un acto para él totalmente incondicionado y absoluto y, por ende, esta suposición y el Yo puesto como primitivo son idénticos. Es sobre lo anterior que entra ya el tema de la intuición, ya que la intuición de sí mismo, al llevar a cabo el acto mediante el cual surge su Yo, se llama intuición intelectual, y esto es aquello que me deja saber algo porque lo hago y se hace; pero esta no puede demostrarse por medio de conceptos ni se puede sacar lo que aquella es de estos, simplemente debe buscarse en sí mismo. Sin embargo, sí se puede demostrar que la intuición intelectual se da en todos los momentos de la conciencia y, además, que es por medio de esta que se logra distinguir mi actuar del objeto del actuar que se encuentra ante mí. No obstante, cabe recalcar, que la intuición intelectual no se da nunca como un acto completo de la conciencia, sino que la intuición intelectual y la intuición sensible necesitan del concepto y estas siempre van acompañadas la una de la otra. Que estas tengan que presentarse unidas se debe a que no es posible encontrarme actuando sin encontrar un objeto (que es sobre el que actúo) en una intuición sensible en la que formo concepto sin que se esboce una imagen de lo que se quiere producir.

Empero, existen enemigos de la intuición intelectual, quienes explican que esta es solo posible con la intuición sensible, cosa que el criticismo no ha de negar. Aunque si se negase la intuición intelectual en mor de este argumento, se negaría entonces también la intuición sensible, puesto que esta no es posible sin la intelectual. Pero otro problema distinto es explicar la posibilidad de la intuición intelectual, que se supone como hecho, sin embargo, esto se hace exclusivamente mostrando en nosotros la ley moral, donde nos representamos el Yo como algo elevado por encima de toda modificación primitiva operada por la ley misma, 
donde le exigimos al Yo un actuar absoluto, fundado solo en él y en nada más, y al que caracterizamos como un principio activo y absoluto.

Al haber entendido lo anterior, podemos decir que el filósofo se contempla a sí mismo en el actuar mediante el cual construye el concepto de sí mismo para sí mismo y, además, que él piensa este actuar. El filósofo es consciente de lo que habla, pero una intuición no da conciencia, solo se es consciente de aquello que se piensa con el concepto. Sobre esto el filósofo tiene un concepto del actuar en general que está en contrastación con el ser, que él ya conoce, pero, a su vez, tiene un concepto del actuar especial de que ahora se trata un actuar de la inteligencia como tal, aunque en modo alguno de un actuar real por medio de la facultad de la práctica. Y esto se debe a que la intuición es la base del concepto, a que no podemos crearnos de un modo absoluto por medio del pensar, ya que solo podemos pensar lo inmediatamente intuido, por lo que un pensar que no tenga por fundamento ninguna intuición no es propiamente pensar. Después de ver esta explicación nos surge la pregunta de hacia dónde se dirige todo pensar, a lo que podemos responder que (i) no se dirige a un ser, ya que si así fuese el Yo no podría pensarse $y$, por ende, toda ciencia que partiera de esto ya sería vacua y nula; pero sobre esto se puede decir que, ya que estos filósofos (los dogmáticos) examinan bajo su lógica al Yo propio de la teoría de la ciencia, han de pensar este concepto,

pero, como vemos, han llegado felizmente a pensarlo [pero luego] tienen que poder pensarlo más porque, de acuerdo con sus reglas, antaño aprendidas de memoria y mal entendidas, no hubiesen debido poder, prefieren negar la posibilidad de una acción, inmediatamente después o en el mismo instante que llevan a cabo, antes que renunciar a las reglas (Fichte, 2013, p. 530).

Por esto, también, la afirmación de que todo pensar se dirige a un ser se contradice a sí misma y, por ende, se anula a sí misma y ha de ser rechazada. Y (ii) que todo pensar parte necesariamente del ser debido a que en todo pensar hay un algo pensado, un objeto del pensar al cual se limita este determinado pensar, por el cual aparece limitado. Pero esta objetividad para el mero pensar conviene también al acto mediante el cual el Yo se construye para sí mismo; es decir, "por medio del pensar obtiene y simplemente para el pensar tiene esta objetividad" (Fichte, 2013, p. 531), por lo que es solo un ser ideal. No obstante, aquí no se debe entender al ser como un ideal sino como un ser real (algo que limite no meramente la actividad ideal del Yo, sino también la que actúa en la práctica), pero es esto último lo que ellos quieren afirmar; que solo algo así puede pensarse, pero si ellos tuvieran razón no sería posible ninguna metafísica, tampoco ninguna conciencia en sí, ni una conciencia en general, ya que no sería posible pensar el concepto del Yo, por lo que tendríamos que dejar de filosofar, y con esto ellos no habrían ganado nada, puesto que su crítica contra el idealismo habría de cesar. 


\section{Referencias}

Fichte, J. G. (2013). Introducción a la teoría de la ciencia. En J. G. Fichte, Fichte (pp. 472-549). Madrid: Gredos. 